\title{
Establishing a benchmark for comparing relative cost-effectiveness of an alternative policy instrument for controlling non-point source pollution
}

\author{
B Grové* and LK Oosthuizen \\ Department of Agricultural Economics, PO Box 339, University of the Free State, Bloemfontein 9301, South Africa
}

\begin{abstract}
Knowledge about economic environmental tradeoffs is a prerequisite to evaluate the relative cost-effectiveness of alternative policy instruments to control non-point source pollution (NPS). Failure to explicitly account for the impact of the spatial combination of alternative management practices on pollution contribution rates while quantifying these tradeoffs may cause relative comparisons between alternative policy instruments to control NPS pollution inappropriate. The main objective of this research is to develop a spatial decision support system able to quantify cost-effective economic environmental tradeoffs of maintaining alternative pollution standards taking the interrelated linkages between various agricultural management practices into account. The system is used to establish a benchmark tradeoff curve by means of which alternative policy instruments to control NPS pollution can be compared to determine their relative cost-effectiveness. Tradeoff analyses indicated that the pollution contribution factor plays a cardinal role in determining pollution abatement cost and therefore the benchmark. The importance of the contribution factor highlights the necessity of taking the interdependencies between management units into account when modelling economic environmental tradeoffs. Catchment level tradeoffs showed that the nitrate water quality indicator can be improved with little cost due to both positive and negative tradeoffs at the sub-catchment level. Significant variability exists at the sub-catchment level when nitrate pollution abatement and abatement cost are concerned. The conclusion is that care should be taken not to compare the relative cost-effectiveness of alternative policy instruments to control NPS pollution based on catchment level tradeoffs alone.
\end{abstract}

Keywords: spatial programming, environment, tradeoffs, irrigation, pollution, contribution factors

\section{Introduction}

Past efforts to protect the quality of South Africa's water resources were concentrated mainly on the control of effluents from point sources. Despite these efforts an apparent deterioration in the water quality of the country's surface waters is being observed (Pegram et al., 1997), reasons being the fact that in many catchments there are zones where non-point source (NPS) contributions are significant or even dominant. Quibell (2000) argues that a lack of legislative and regulatory authority on the one hand and poorly defined linkages between implementable management actions and the processes that lead to NPS pollution on the other hand have hampered the management of NPS pollution sources in the past.

The National Water Act (Act36 of 1998) for the first time provides the legislative means to target NPS pollution with specific source-directed measures (Quibell, 2000). No specific differentiation is made between point-source and NPS pollution in the National Water Act and allows for the development of source-specific procedures that address both point-source and NPS pollution from the source. However, it is difficult to design policy to control agricultural NPS pollution. In part this is due to the complex relationship between agricultural production and damages from water pollution involving physical, biological and economic links. How well NPS pollution control policy performs often depends on how well these links are understood

\footnotetext{
To whom all correspondence should be addressed.

III +2751 401-3359; fax: +2751 401-3473;

e-mail: groveb.sci@ufs.ac.za

Received 11 January 2007; accepted in revised form 27 July 2007.
}

(Ribaudo et al., 1999). Economically efficient solutions are usually not achievable because no market for water quality exists and therefore the benefit function from improving water quality is rarely available if at all. Tietenberg (2000) cautions the use of non-market valuation techniques to quantify these benefits arguing that while these methods may provide estimates that are good enough to indicate that the benefits from water quality improvements are large and worth pursuing, it may not be reliable enough to use in choosing an economically efficient level of pollution. Using the correct benefits is especially important because pollution abatement costs are high. In the absence of reliable benefit estimates a method commonly used to provide information regarding economic environmental tradeoffs is to conduct cost effectiveness analysis (Tietenberg, 2000). Environmental policies are cost-effective if they achieve some measurable objectives or goals at least cost. Cost-effective outcomes define actions that would optimally be taken to satisfy NPS pollution policy goals in an ideal world where the set of policy instruments is not restricted and there are no transaction costs associated with implementing optimally designed policies (Ribaudo et al., 1999). Given these conditions cost-effective solutions are rarely attained in practice. As a second-best alternative the best possible outcome would achieve policy goals at lowest cost, given the types of instruments that are used and the cost associated with using them. While second-best alternatives are optimal in practice, their economic performance in the sense of being able to achieve a specific goal at least cost is still measured relative to the ideal of a cost-effective baseline (Ribaudo et al., 1999). Thus, a cost-effective solution provides a benchmark to compare the cost-effectiveness of alternative policy instruments that are used to combat pollution. 
Knowledge about economic environmental tradeoffs is a prerequisite to evaluate the cost-effectiveness of alternative policy instruments to control NPS pollution. Typically information on the cost-effectiveness is generated through the combined use of mathematical programming techniques and models that are able to quantify the environmental impacts of alternative management strategies (Lacroix et al., 2006; Bonham et al., 2004; Westra and Olson, 2001,). Early efforts to quantify these tradeoffs revolved around the reduction of pollution emissions using aggregated field-scale emissions thereby ignoring all the other processes that yield the final water quality. The implication of ignoring these processes is that areas with high field-scale emissions may not contribute significantly to water pollution at a specific location. Relative comparisons between alternative policy instruments may therefore be inappropriate when ignoring the interrelated linkages between agricultural production practices and pollution damage. Qiu and Prato (1999) used an NPS pollution simulation model to generate information for a spatial mathematical programming model to generate cost-effective tradeoff curves. These researchers aggregated the results of different hydrological response units based on exogenously determined contribution rates thereby assuming that management practices will not affect contribution rates. However, in irrigated agriculture different combinations of management practices may alter contribution rates. The main objective of this research is to develop a spatial decision support system able to quantify cost-effective economic environmental tradeoffs of maintaining alternative pollution standards taking the interrelated linkages between various agricultural management practices into account. More specifically the procedures of Qiu and Prato (1999) are augmented to allow management practices to change contribution rates. The quantified tradeoff curves provide an upper benchmark with which alternative policy instruments to control NPS pollution can be compared to determine their relative cost-effectiveness.

\section{Conceptual framework and model specifications}

Segerson (1988) was the first to propose the use of an ambientbased tax to control NPS pollution. Her research showed that a uniform tax based on ambient water quality can achieve an efficient level of NPS pollution in a catchment with multiple polluters only when the marginal benefits of abating pollution are constant. Horan et al. (1998) extended Segerson's analysis by exploring the design of uniform ambient-based taxes when each firm has a multiple choice set. Although the polluters pay a uniform marginal tax rate per unit of additional ambient pollution the correct marginal incentives are maintained since the polluters do not pay the same rate per unit of pollution abatement (Segerson, 1988). The latter depends on each polluter's contribution to marginal ambient water quality levels.

Qiu (1996) used the concept that each polluter (catchment) contributes differently to marginal water-quality problems to derive a conceptual framework with variable economic incentives that allows for the implementation of the tax at sub-catchment level. Following Qiu (1996) the least-cost framework with variable economic incentives can be developed by introducing the concept of pollution contribution rate.

Suppose there are $J$ farms which have their own production activities which generate emissions. Let $y^{j}$ be the production bundle of farm $j$ with $y_{n}^{j}$ being the $n^{\text {th }}$ element (positive or negative) of that vector. Positive activities represent outputs and negative ones are inputs. There are $N$ goods or activities, i.e., $n=1, \ldots, N$. Emissions by farm $j$ are nonnegative and are denoted by $z^{j}$. Farm $j$ 's production set is given implicitly by $f^{j}\left(y^{j}, z^{j}\right) \leq 0$. These relationships become equalities when the farms fully exploit their production abilities, which are assumed here. It is assumed that the objective of society is to limit the aggregate pollution to $Z$. Aggregate pollution is a continuous and differentiable function of emissions generated by all farms, $h(z)$, where $z$ is a vector of emissions generated by farms. The constraint on the relationship between emission at all farms and aggregate pollution is:

$$
h(z) \leq Z^{*}
$$

Thus, the social Lagrangian is:

$$
L=\sum_{j=1}^{J} p y^{j}-\sum_{j=1}^{J} \alpha^{j} f^{j}\left(y^{j}, z^{j}\right)-\mu\left[h(z)-Z^{*}\right]
$$

with the following equations specifying the first-order conditions:

$$
\begin{array}{ll}
p_{n}-\alpha^{j} f_{n}^{j}=0 & \text { for all } n \text { and } j \\
-\mu h_{z}^{j}-\alpha^{j} f_{z}^{j}=0 & \text { for all } j
\end{array}
$$

where:

$p \quad$ price vector $(1 \times N)$

$\alpha, \mu \quad$ appropriate Lagrange multipliers

$h_{z}^{j} \quad$ partial derivative of the contribution function, $h(z)$, with respect to $z^{j}$ and interpreted as farm $j$ 's pollution contribution rate.

The optimal economic incentive $\left(s_{j}^{*}\right)$ for farm $j$ with minimum costs is shown to be:

$$
s_{j}^{*}=\mu^{*} h_{z}^{j}
$$

The optimal economic incentives vary across farms when farms have different contributions to aggregate pollution. Similarly, a system of standards on emissions from all farms can be derived as the dual of the variable economic incentive using the same framework presented above. Qiu and Prato (1999) implemented the above theoretical framework by calculating pollution indicators using a two-step procedure. With the $1^{\text {st }}$ step, the concentration of nitrate generated by each hydrological response unit is calculated. In the $2^{\text {nd }}$ step, the sub-catchment water quality indicators are calculated using area weighting. However, if runoff is altered through a specific management practice, area weighting is an inappropriate procedure to calculate sub-catchment water quality indicators. Weighting should then rather be done according to runoff.

Given the above theoretical development the following empirical optimisation model is constructed to determine costeffective economic environmental tradeoffs:

$$
\begin{aligned}
& \sum_{s} \sum_{h} \sum_{l} \sum_{j} \sum_{p} \sum_{n} \sum_{i r} Q_{s, h, l, j, p, n, i r} \operatorname{gm}_{s, h, l, j, p, n, i r}=Z \\
& \sum_{j} \sum_{p} \sum_{n} \sum_{i r} Q_{s, h, l, j, p, n, i r} l u_{j, p, t} \leq \text { area }_{s, h, l} \\
& \sum_{s} \sum_{h} \sum_{l} \sum_{n} \sum_{i r} Q_{s, h, l, j, p, n, i r} / \sum_{s} \sum_{h} \sum_{l} \operatorname{area}_{s, h, l} * \text { util } \leq \operatorname{perc}_{j, p} \\
& \sum_{s} \sum_{h} \sum_{l} \sum_{n} \sum_{i r} Q_{s, h, l, j, p, n, i r} \operatorname{gir}_{s, h, l, j, p, i r} \leq \text { alloc }_{s} \\
& b s i_{s}-A_{s}-P_{s} \geq 0 \\
& \sum_{s} A_{s} C_{s} \geq b i \alpha \\
& \sum_{h} \sum_{l} \sum_{j} \sum_{p} \sum_{n} \sum_{i r} Q_{s, h, l, j, p, n, i r} \text { wyld }_{s, h, l, j, p, n, i r}=S W Y L D_{s} \\
& \sum_{h} \sum_{l} \sum_{j} \sum_{p} \sum_{n} \sum_{i r} * Q_{s, h l, j, p, n, i r} \text { nloss }_{s, h, l, j, p, n, i r}=S E M_{s} \\
& S W Y L D_{s} P_{s}=S E M_{s}
\end{aligned}
$$




$$
\sum_{s s} S W Y L D_{s s} * C_{s}=S W Y L D_{s}
$$

where:

$Q_{s, h, l, j, p, n, i r} \quad$ quantity of crop $j$ planted in month $p$ in subcatchment $s$ utilising hydrological response unit h, land type $l, n$ kilogram of nitrogen and ir $\mathrm{mm}$ of water

$g m_{s, h, l, j, p, n, i r}$ gross margin of crop $j$ planted in month $p$ in sub-catchment $s$ utilising hydrological response unit $h$, land type $l, n$ kilogram of nitrogen and ir $\mathrm{mm}$ of water

$l u_{j, p, t} \quad$ land utilisation in month $t$ by crop $j$ planted in month $p$

area $_{s, h, l} \quad$ area available of hydrological response unit $h$ consisting of land-type $l$ in sub-catchment $s$

util total catchment land utilisation factor

$\operatorname{perc}_{j, p} \quad$ maximum percentage of crop $j$ planted in month $p$ in crop mix

$\operatorname{gir}_{s, h, l, j, p, i r} \quad$ gross irrigation requirement of crop $j$ planted in month $p$ in sub-catchment $s$ utilising hydrological response unit $h$, land type $l, n$ kilogram of nitrogen and $i r \mathrm{~mm}$ of water

alloc water allocated to sub-catchment $s$

$b_{s i} \quad$ baseline water quality indicator in sub-catchment $s$

$A_{s} \quad$ pollution abatement by sub-catchment $s$

$P_{s} \quad$ pollution generated by sub-catchment $s$

$C_{s}^{s} \quad$ pollution contribution rate of sub-catchment $s$

$b i \quad$ baseline total catchment pollution indicator

$\alpha \quad$ necessary pollution abatement level

wyld $_{s, h, l, j, p, n, i r}$ runoff generated by growing crop $j$ planted in month $p$ in sub-catchment $s$ utilising hydrological response unit $h$, land type $l, n$ kilogram of nitrogen and $i r \mathrm{~mm}$ of water

nloss $_{s, h, l, j, p, n, i r}$ nitrate emissions generated by growing crop $j$ planted in month $p$ in sub-catchment $s$ utilising hydrological response unit $h$, land type $l, n$ kilogram of nitrogen and ir mm of water

The convention is followed in the above specification whereby capital letters denote variables and small letters denote data parameters or tables. The baseline model comprised Eqs. (6) to (9) and is used to determine baseline nitrate pollution indicators at the sub-catchment and total catchment level from which water quality improvements are modelled. Total catchment gross margins are optimised with the baseline model given constraints regarding total land and water availability, as well as maximum specific crop area utilisation factors. The area utilisation factors are used to calibrate the model to better represent the relative importance between different crops. The other equations are added to the second model to determine cost-effective economic environmental tradeoffs. More specifically, Eqs. (12) to (14) are used to determine subcatchment pollution indicators as a function of nitrate loss and runoff, whereas Eq. (15) is used to determine each sub-catchment's contribution as a function of runoff. Equation (11) ensures that the sum of weighted pollution abatement by each sub-catchment is greater or equal to the desired level of pollution abatement, while Eq. (10) ensures that each sub-catchment may not pollute more than baseline levels. The model is solved with MINOS (Murtagh and Saunders, 1987) using the general algebraic modelling system (GAMS) (Brooke et al., 1998).

\section{Data development}

The research was conducted in the Gamtoos River catchment situated about $100 \mathrm{~km}$ west of Port Elizabeth on the Eastern Cape coast between latitude $33^{\circ} 58^{\prime}$ and longitude $25^{\circ} 01^{\prime}$ East. The Gamtoos River is formed by the confluence of the Kouga and Groot Rivers. The drainage area of the $70 \mathrm{~km}$-long Gamtoos River, which is surrounded by the Baviaanskloof Mountains, constitutes an area $1357 \mathrm{~km}^{2}$. Typically the entire valley is divided into three sub-districts namely Patensie, Hanky and Loerie/Mondplaas with a total listed irrigation area of 7412 ha. The most important crops grown in the valley are citrus, potatoes, maize, wheat and other vegetables. Micro- and drip-irrigation are predominantly used to irrigate citrus while the other crops are grown using centre-pivot irrigation.

The soil and water assessment tool (SWAT) (Neitsch et al., 2001) was used to generate the necessary input parameters for the spatial optimisation model. Spatial analyst was used to automatically delineate $22 \mathrm{sub}$-catchments from the confluence of the Gamtoos and the Groot Rivers downstream to the coast using a digital elevation model (DEM) with a $20 \mathrm{~m}$ resolution. Model inputs were then developed for each of the sub-catchments.

Schulze et al. (1995) developed hydrological attributes for the land-type database of the Institute for Soil, Climate and Water (ISCW) which were used as the basis of soils information. After the soils information is specified the land use determines the purpose for which the soil is used. At first the land use was divided into two broad categories, irrigated and non-irrigated. The irrigation areas in the Gamtoos irrigation valley were digitised from 1:50 000 digital ortho-photo images obtained from the Department of Land Affairs, Chief Directorate, Surveys and Mapping. Once the irrigation theme was established it was combined with the catchment theme to determine the non-irrigated areas using GIS processing. The impact of non-irrigated land was held constant in this research. Once these inputs are specified each of the sub-catchments are further partitioned into hydrological response units (HRUs), which are lumped areas within the sub-catchment with different hydrological impacts that are comprised of unique land cover, soil and management combinations. HRUs allow for a better physical representation of the catchment since each HRU is simulated separately after which the results are aggregated to determine the resulting pollution loading for the sub-catchment as a whole. In total 129 HRUs are developed of which 53 are used for irrigation purposes.

The effects of 229 alternative crop, water and fertiliser input combinations on nitrate pollution parameters were simulated with SWAT using 15 years of historical weather data. The same management alternative is applied to all the different HRUs that are used for crop production while keeping the impact of the others constant when simulating the water quality impacts of a specific management alternative. Thus, a separate simulation is needed for each of the management scenarios, which amounts to 228 SWAT runs. Monthly results for each of the HRUs are saved in the basins.sbs file that is created during each SWAT run. The basins.sbs files contain all the necessary information needed to quantify the pollution impact of the alternative management practices, which are needed by the optimisation model. Simulated results showed that crop yield is not very responsive to alternative management scenarios and therefore procedures proposed by Qui (1996) were used to determine crop yield based on potential crop yield and a yield indexed developed from the simulated SWAT crop yields. 


\section{Results}

\section{Baseline}

Given the specification of the mathematical programming model outlined above baseline pollution levels are needed from which to model the economic environmental tradeoffs concerning nitrate water quality improvement. Since only two crops are used to approximate the impact of alternative strategies to lessen the harmful effects of nitrate pollution, the actual land use cannot be used as a baseline. Instead a programming model with no constraints on pollution was used to determine the optimal land use for the Gamtoos irrigation valley, given only potato and cabbage crops can be planted during different time periods.

When using potato and cabbage as proxies for the other crops grown in the Gamtoos catchment a total gross margin above specified cost of R325 m. is generated. In total 9690 ha is irrigated throughout the year giving a land utilisation factor of 1.43. Constraints in the programming model on the maximum percentage of hectares planted to a certain crop with a specific planting date ensure that the proportion between potatoes and cabbage in the baseline portrays the relative importance of these crops in the catchment. In total 1805 ha of cabbage and 7885 ha of potatoes are planted in the optimal baseline solution. Gross margins per hectare planted in a sub-catchment range from a minimum of R23 240 in Sub13 (sub-catchment) to a maximum of R43 108 in Sub 5. The average gross margin is R31 765/ha.

In the next section the nitrate water quality indicators at the catchment and sub-catchment level calculated from the optimised baseline land use with only potatoes an cabbage are used as baseline pollution levels from which economic environmental tradeoffs are quantified.

\section{Cost-effective economic environmental tradeoffs}

Recall that a cost-effective pollution control policy was previously defined as one which achieves a specific pollution level at minimum cost. Thus, the main objective of this section is to determine the spatial allocation of alternative management practices that will achieve a specific reduction in the water quality indicator relative to the baseline catchment indicator determined in the previous section at least cost. The economic environmental tradeoffs are evaluated with the programming model specified above by lowering the baseline nitrate water quality indicator through the multiplication of appropriate reduction levels. The programming model is structured such that each sub-catchment may not pollute more than the baseline pollution levels. However, the pollution contribution rates are not kept constant since each sub-catchment's contribution rate may be altered through changes in irrigation scheduling strategies or when some land has to go out of production.

\section{Total catchment level}

The typical downward sloping tradeoff curve between nitrate water quality improvement at the catchment outlet and total gross margins for the total catchment is shown in Fig. 1.

From Fig. 1 it is evident that an improvement of $20 \%$ in the nitrate water quality indicator at the catchment outlet is possible without reducing total catchment gross margins significantly. To improve the water quality indicator by $20 \%$ total catchment gross margin is reduced by only $\mathrm{R} 1 \mathrm{~m}$. Total catchment gross margin is reduced more severely between the $20 \%$ and $50 \%$ levels of improving the catchment water quality indicator.

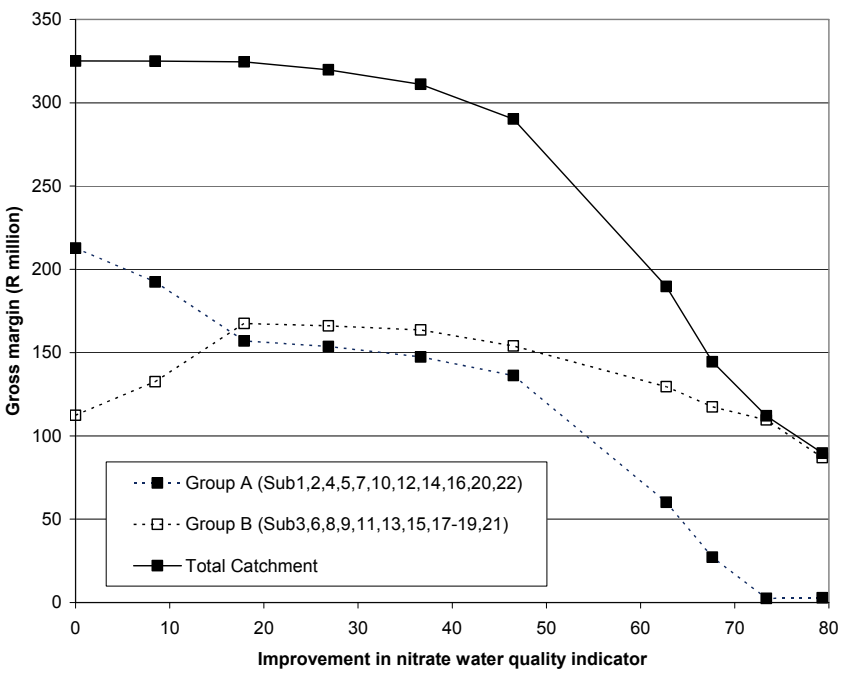

Figure 1

Catchment and sub-catchment level cost-effective economic environmental tradeoffs of improving nitrate water quality in the Gamtoos irrigation valley

Improving water quality by another 30 percentage points from the $20 \%$ level will reduce total catchment gross margins by another R35 m. from R325 m. to R290 m. Up to a 50\% improvement in the water quality indicator farmers are able to minimise abatement cost through their choice of management practices and reallocating production spatially over the catchment without lowering the land utilisation factor of 1.43 established in the baseline. In order to improve water quality by more than $50 \%$ some land has to go out of production, resulting in drastic reductions in total catchment gross margin. Abatement cost amounts to $\mathrm{R} 135 \mathrm{~m}$. to improve water quality by $70 \%$.

Results from the above discussion clearly show that the programming model is capable of quantifying the necessary economic environmental tradeoffs of increasing water quality. One can conclude that water quality improvements of up to $20 \%$ will come at a low cost given that the spatial allocation of the management practices is obtained. However, more important are the tradeoffs at the sub-catchment level when trying to implement socially acceptable pollution abatement policies especially if it means that some farmers have to cease farming while others are increasing their production.

\section{Sub-catchment level}

Tradeoffs at the sub-catchment level are used to explain the tradeoff at the catchment level. To gain a better understanding of the type of tradeoffs that exist at the sub-catchment level subcatchments were grouped into two groups based on the shape of their tradeoffs up to the $20 \%$ pollution abatement level. The tradeoffs that exist within these two groups are also shown in Fig. 1.

Significant tradeoffs exist for both groups with the main difference being the fact that both positive and negative tradeoffs are modelled up to a $20 \%$ improvement in the nitrate water quality indicator. For Group A total gross margins are reduced by $\mathrm{R} 56 \mathrm{~m}$. from $\mathrm{R} 213 \mathrm{~m}$. to $\mathrm{R} 157 \mathrm{~m}$., which is $\mathrm{R} 21 \mathrm{~m}$. more than at the total catchment level. In contrast the total gross margin for Group B increases by R $55 \mathrm{~m}$. resulting in a net effect of R $1 \mathrm{~m}$. at the total catchment level.

The inverse tradeoff modelled is mainly due to a decrease in the area under irrigation in the first group and an equal increase 
in the area in the second group. Thus, a spatial redistribution of production takes place without lowering the land utilisation factor. Most of the crops in the Gamtoos valley are grown on contract. Only a limited number of contracts are available each year and therefore it is possible that some catchments with lower abatement cost may acquire more production contracts. Mostly cabbage areas are spatially redistributed between the two groups. Within the sub-catchments of each group and between the two groups, tradeoffs between fertiliser application rates, irrigation level, gross margins, nitrate emissions and each catchment's pollution contribution rate determine the unique spatial land use that complies with the nitrate water quality indicator levels set at each sub-catchment and at the total catchment outlet. An important result is that although the total amount of nitrate emission in Group B increased due to an increase in area irrigated each sub-catchment still complied with the water quality indicator. Thus, changes in irrigation schedules result in increased dilution capacity.

Once pollution reduction is shifted between different catchments the tradeoffs tend to stabilise up to a $50 \%$ pollution abatement level. Beyond the 50\% level total gross margins for the sub-catchments in Group A are reduced very significantly due to reductions in the area irrigated while those of the sub-catchments in the second group remain relatively constant.

The above results clearly indicate that despite the fact that relatively little tradeoff exists at the catchment level significant tradeoffs exist at the sub-catchment level. When expressed per hectare planted the abatement cost at the catchment level is R103 whereas it is R5 779 for Group A. Given the high cost in Group A it is concluded that the choice of pollution abatement levels based on catchment level tradeoffs may not be acceptable at the sub-catchment level because it will cause some farmers to cease their farming activities while others are expanding their production. Furthermore using a reduction in pollution emissions as policy goal may result in tradeoff curves with high abatement costs since it ignores the dilution capacity of water and changes in contribution rates.

Figure 1 gives a clear indication of the positive and negative tradeoffs associated with increasing water quality but gives no indication of the spatial variability of the magnitude of pollution abatement necessary to comply with specific water quality standards as well as the associated economic impact.

\section{Spatial variability}

Figure 2 shows the spatial variability in pollution abatement for each of the 22 sub-catchments for three different pollution abatement levels at the total catchment level.

If the nitrate water quality indicator has to improve by $10 \%$ it is clear that some sub-catchments need not abate any pollution. The variability in the magnitude of the sub-catchments that needs to abate pollution to comply with the water quality standard at the catchment outlet is significant. Sub17 has to abate about $55 \%$ of its pollution whereas Sub 9 has to reduce its pollution levels by about $4 \%$. As the water quality standard at the catchment outlet is increased more sub-catchments need to abate pollution. To improve the overall water quality indicator by $50 \%$ all the sub-catchments need to abate some pollution with most of them having to abate their pollution by more than $40 \%$ to comply with the standard at the catchment outlet. All the sub-catchments have to abate pollution when improving the water quality indicator by $90 \%$. Furthermore some catchments will have to go out of production to comply with the water quality standard. An abatement level of $100 \%$ is modelled for

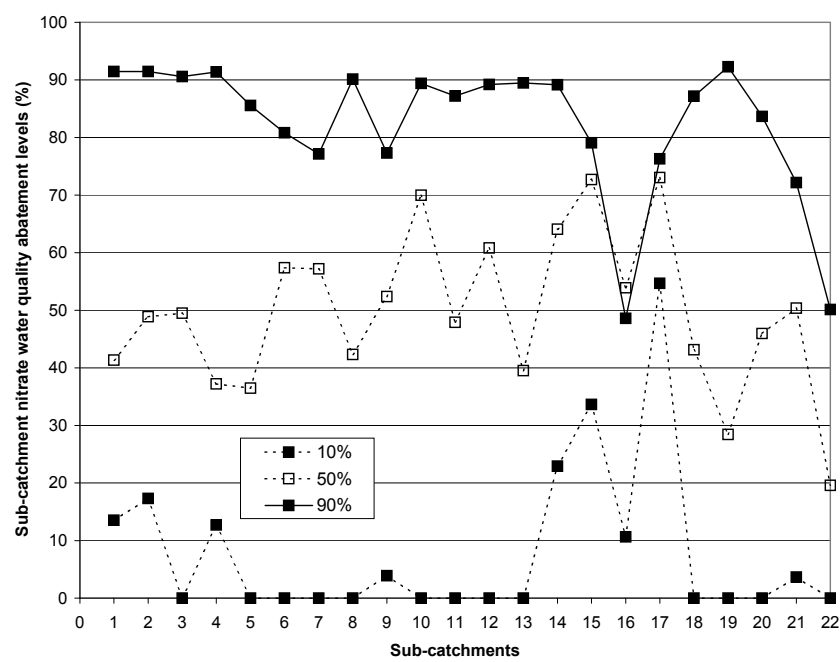

Figure 2

Spatial variability of sub-catchment pollution abatement when complying with three different water quality abatement levels at the catchment outlet

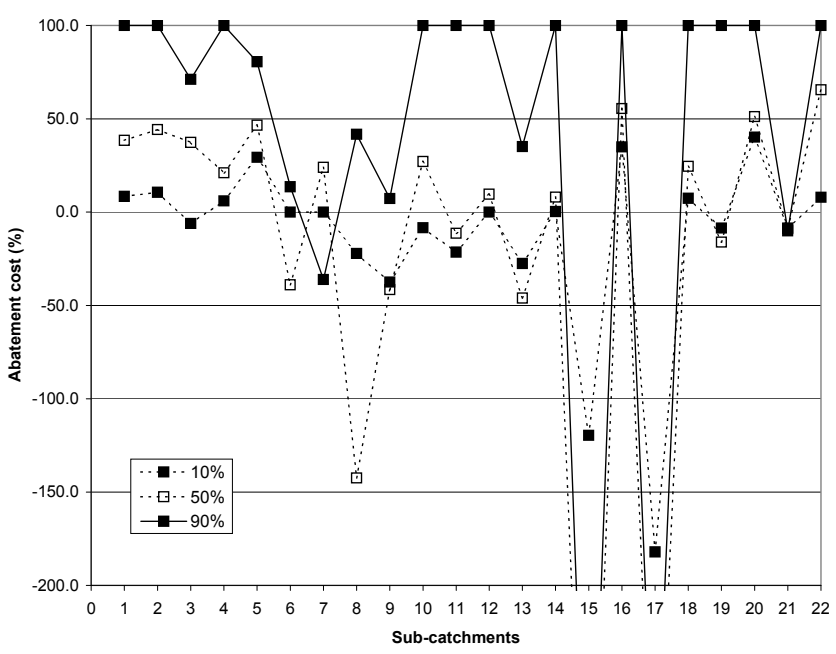

Figure 3

Spatial variability of sub-catchment abatement cost when complying with three different water quality abatement levels at the catchment outlet

neither of the sub-catchments due to lower bounds on the amount of runoff from each sub-catchment to prohibit division by zero in the programming model. The pollution contribution factors optimised for these sub-catchments are, however, so low that the water quality abatement levels have little effect on the overall result. The conclusion is drawn that water quality abatement at the sub-catchment level will not give a true indication of water quality improvement at the catchment outlet if evaluated in isolation of the specific catchment's contribution factor. Also significant variation exists in sub-catchment pollution abatement levels to comply with the catchment water quality standard. The spatial variability of gross margins associated with the pollution abatement levels at sub-catchment level is evaluated next.

Figure 3 shows the associated variability in abatement cost for the three different levels of pollution abatement at the catchment outlet. A negative abatement percentage for a specific catchment represents gains above the specified baseline gross margins. From Fig. 3 it is clear that abatement cost is high which may be detrimental to farming business profitability. 
Also abatement cost is highly variable between sub-catchments. None of the gross margins for the three pollution abatement levels follow pollution abatement particularly well (shown in Fig. 2). For instance Sub 7 and Sub 9 has to abate more or less the same amount of pollution to improve water quality by $90 \%$ but Sub 7 has a gross margin of about $50 \%$ more than baseline level whereas Sub 9 has an abatement cost of about $50 \%$. Percentage reductions in gross margins are not proportional to pollution abatement because of different pollution baseline levels and the fact that sub-catchment abatement cost is a function of the pollution abatement level and its contributing factor.

The conclusion is made that high abatement cost may cause farming to be unprofitable in some sub-catchments. Furthermore each sub-catchment's baseline pollution levels as well its contribution to the pollution at the outlet of the Gamtoos are important factors determining pollution abatement cost. When interpreted differently the contribution factor means the spatial location of one sub-catchment relative to another

\section{Conclusions and implications}

The main concern of this paper was to develop a modelling framework that will allow advisors in the field of pollution control to establish a cost effective benchmark with which alternative policy instruments can be compared to determine their relative cost-effectiveness. Cognisance should be taken of the fact that the pollution contribution factor plays a cardinal role in determining pollution abatement cost. The importance of the contribution factor highlights the necessity of taking the interdependencies between management units into account when modelling economic environmental tradeoffs. Lichtenberg (2000) acknowledges this result and reasons that ignoring transport linkages to receiving water bodies as well as the link between emitted pollutants and ambient pollution levels and therefore the interrelated linkages between agricultural production practices and pollution damage may stem relative comparisons between alternative policies inappropriate. The establishment of the cost-effective tradeoffs in an ideal world where the set of policy instruments is not restricted and there are no transaction costs associated with implementing optimally designed policies present the first step towards the evaluation of the relative cost effectiveness of alternative instruments to control NPS pollution. A logical next step is to alter the model to quantify economic environmental tradeoffs of such instruments.

Another important result that emanates from the tradeoff analyses is the significant differences between total catchment and sub-catchment level tradeoffs. The sub-catchment level tradeoffs explaining the catchment level tradeoffs are much more important in determining irrigation farming profitability and therefore the impact on the economy of the region. Although catchments and sub-catchments constitute logical planning units from an environmental viewpoint it does not coincide with the management units and political boundaries. However, water pollution is determined by decisions made within political boundaries and management units. The policy challenge is to harmonise economic development within political boundaries as well as decisions made at farm level with sustainable environmental protection. Brooks et al. (1994) reason that this should be done by realistically integrating these views by adapting catchment management to economic and social realities. The conclusion is that care should be taken not to compare the relative costeffectiveness of alternative policy instruments to control NPS pollution based on catchment level tradeoffs alone.

\section{Acknowledgements}

Financial assistance provided by the Water Research Commission (WRC) is gratefully acknowledged. The views of the authors do not necessarily reflect those of the WRC.

\section{References}

BOHAN J, BOSCH D and PEASE J (2004) Cost effectiveness of nutrient management and buffers: comparisons of four spatial scenarios. Proc. American Agricultural Economics Association Annual Meeting. 1-4 August, Denver, USA.

BROOKS KN, FFOLIOTT PE, GREGERSON HM and EASTER KW (1994) Policies for Sustainable Development: The Role of Watershed Management. Policy Brief No 6. EPAT/MUCIA Research and Training, University of Wisconsin, Madison, USA.

DEPARTMENT OF WATER AFFAIRS AND FORESTRY (1998) SOUTH AFRICA (Republic). National Water Act. Act 36 of 1998. 20 August 1998.

HORAN RD, SHORTLE JS and ABLER DG (1998) Ambient taxes when polluters have multiple choices. J. Environ. Econ. Manage. 36 186-199.

LACROIX A, BEAUDOIN N and MAKOWSKI D (2006) Agricultural water nonpoint pollution control under uncertainty and climate variability. Ecol. Econ. 53 115-127.

LICHTENBERG E (2000) Agriculture and the Environment. Working Paper No 00-15. Department of Agricultural and Resource Economics, University of Maryland, College Park, Maryland, USA.

MURTAGH BA AND SAUNDERS MA (1987) MINOS 5.0 User's Guide. Report SOL 83-20, Department of Operations Research, Stanford University, 1983 (Revised as MINOS 5.1 User's Guide, Report SOL 83-20R).

NEITSCH SL, ARNOLD JG, KINIRY JR and WILLIAMS JR (2001) Soil and Water Assessment Tool: User's Manual. Version 2000. Blackland Research Center, Texas Agricultural Experiment Station, Temple, Texas.

PEGRAM GC, QUIBELL G and GÖRGENS AHM (1997) The Development of a Guide for the Assessment of Nonpoint Sources in South Africa. Proc. $8^{\text {th }}$ S. Afr. Nat.Hydrol. Symp. 17-19 November, Sanlam Conference Centre, University of Pretoria, South Africa.

QIU Z (1996) Integrated Assessment of Agricultural Nonpoint Source Pollution in Goodwater Creek Watershed, Missouri. Ph.D. thesis. Faculty of the Graduate School, University of Missouri-Columbia.

QIU Z and PRATO T (1999) Accounting for spatial characteristics of watershed in evaluating water pollution abatement policies. J. Agric. Appl. Econ. 34 (1999) 161-175.

QUIBELL G (2000) Managing the root causes of nonpoint source pollution - Some experiences from the project to manage water quality effects of densely populated settlements. Proc. WISA 2000 Bienn. Conf. 28 May to 1 June, Sun City, South Africa.

RIBAUDO MO, HORAN RD and SMITH ME (1999) Economics of Water Quality Protection from Nonpoint Sources: Theory and Practice. Agricultural Economics Report No 782. Resource Economics Division, Economic Research Service, US Department of Agriculture, Washington DC, USA.

SCHULZE RE, ANGUS GR and GUY RM (1995) Soils. Hydrology and Agrohydrology, A Text to Accompany the ACRU 3.00 Agrohydrology Modelling System. Chapter 5. University of Natal, Pietermaritzburg, South Africa. 1-40.

SEGERSON K (1988) Uncertainty and incentives for nonpoint pollution control. J. Environ. Econ. Manage. 15 87-98.

SHORTLE JS and GRIFFIN RC (2001) Irrigated Agriculture and the Environment. The Management of Water Resources. An Elgar Reference Collection.

TIETENBERG T (2000) Environmental and Natural Resource Economics ( $5^{\text {th }}$ edn.) Glenview, Illinois: Scott, Foresman and Company.

WESTRA JV and OLSON KD (2001) Enviro-economic analysis of phosphorus nonpoint source pollution. Proc. American Agricultural Economics Association Annual Meeting. 5-8 August 2001, Chicago, USA. 